\title{
Revisiting preview search at isoluminance: New onsets are not necessary for the preview advantage
}

\author{
JASON J. BRAITHWAITE, GLYN W. HUMPHREYS, DERRICK G. WATSON, and JOHAN HULLEMAN \\ University of Birmingham, Birmingham, England
}

\begin{abstract}
It has been argued that search performance under preview conditions relies on automatic capture by luminance onsets (Donk \& Theeuwes, 2001). We present three experiments in which preview search was examined with both isoluminant and nonisoluminant items (e.g., as defined by luminance onsets). Experiment 1 provided evidence against the automatic capture of attention by onsets. Search benefited when onset previews were followed by new onset stimuli, as compared with a full-set baseline matched for the number of new onsets but in which half the distractors appeared simultaneously at isoluminance. Furthermore, both Experiments 1 and 2 established a preview advantage when isoluminant targets followed onset previews, when compared with appropriate full-set baselines. Experiment 3 replicated this result, while showing that the preview benefit was disrupted by dual-task interference. The data indicate that new onsets are not necessary to generate a preview advantage in search. We discuss the data in terms of search's benefiting from active inhibition of old onset-defined stimuli.
\end{abstract}

In a typical serial visual search task, observers are presented with a single display of items containing distractor items and a target item. In difficult search tasks, reaction times (RTs) increase as the number of distractors increases. However, recent evidence has suggested that search efficiency can be considerably improved if observers are given a preview of half the distractors before the other distractors and the target are presented (Olivers, Watson, \& Humphreys, 1999; Theeuwes, Kramer, \& Atchley, 1998; Watson \& Humphreys, 1997, 1998, 2002). Under these circumstances, search can be as efficient as when only the second set of items is presented and much more efficient than when the items appear together in the full combined display (a full-set search condition). This is the preview benefit in search. Currently, there is a feverish, ongoing debate about the factors underlying preview search.

Watson and Humphreys (1997) originally proposed that, for stationary items, the benefit was due, in part, to inhibition of the locations of the old items - a process termed visual marking (Watson \& Humphreys, 1997, 1998, 2000, 2002; see also Olivers et al., 1999; Theeuwes et al., 1998). Due to this inhibition, the new items gained an additional priority in search that complemented the influence of any capture mechanisms on performance. More recently, investigators have argued that other properties of the old

This research was supported by a British Academy fellowship awarded to the first author and by an MRC grant awarded to the second author. We thank James Hoffman, Mieke Donk, and two anonymous reviewers for comments on earlier versions of this article. Correspondence concerning this article should be addressed to J. J. Braithwaite, School of Psychology, University of Birmingham, Edgbaston, Birmingham B15 2TT, England (e-mail: j.j.braithwaite@bham.ac.uk). items may be inhibited, in addition to the locationsincluding their color and group membership (Braithwaite, 2002; Braithwaite \& Humphreys, 2003; Braithwaite, Humphreys, \& Hodsoll, 2003, 2004; Braithwaite, Humphreys, \& Hulleman, 2005; Gibson \& Jiang, 2001; Olivers \& Humphreys, 2002, 2003; Watson, 2001). Evidence for inhibitory effects in the preview paradigm comes from studies in which probe dot procedures were used to track where attention was allocated in displays. These studies have shown that detection is worse when probes fall at the locations of old items, relative to when they fall at the locations of new stimuli (Braithwaite et al., 2005; Humphreys, Jung Stalmann, \& Olivers, 2004; Olivers \& Humphreys, 2002; Watson \& Humphreys, 2000). Interestingly, this deficit in probe detection at old locations is found when participants are engaged in a search task in which new items must be prioritized. It is not found when probe detection is the primary task. This, in turn, suggests that the preview benefit is influenced by the intention of participants to prioritize the new and to ignore the old stimuli. In addition to any intentional inhibition, Braithwaite and colleagues (Braithwaite \& Humphreys, 2003; Braithwaite et al., 2003, 2004) have provided evidence for intentional anticipation of the features of new stimuli. When the old and the new items in preview search share features, the search of new items can be slowed (Braithwaite \& Humphreys, 2003; Braithwaite et al., 2003, 2004; Braithwaite et al., 2005; Gibson \& Jiang, 2001; Olivers \& Humphreys, 2002). Braithwaite and Humphreys (2003) showed that this slowing, from feature-based similarity, was counteracted to some degree when participants could anticipate the target's features (see Atchley, Jones, \& Hoffman, 2003, for further evidence of goal-directed processes under preview search conditions). 
In contrast to the idea that there is either intentional inhibition or intentional prioritization of (respectively) old and new items, Donk and Theeuwes (2001) have argued that the preview benefit reflects automatic attentional capture by new onsets. They examined preview search when the stimuli were isoluminant with the background. There were three conditions: (1) Both the preview and the search displays were isoluminant to their background, so that there were no abrupt onset cues in either display; (2) the preview arrived with an abrupt onset, but the search display did not; and (3) the preview display was isoluminant, whereas the search display alone arrived with an abrupt onset. They found that the old items had an impact on search when both the preview and the search displays or the search items alone were isoluminant with the background. On the basis of this finding, Donk and Theeuwes argued that new onsets were necessary to establish a preview advantage, and they attributed this to attentional capture by new onsets (see also Yantis, 1993, 1996).

However, these data are also consistent with an inhibitory visual-marking account of the preview benefit, if we assume that, in order to inhibit and filter out irrelevant information, the items must be represented in a system that codes luminance differences and is sensitive to dynamic change (Watson \& Humphreys, 2002; see also Watson, Humphreys, \& Olivers, 2003). By this account, inhibition of old items would increase the signal (new item) to noise (distractor) ratio for search displays defined by onsets, improving the ability of onset stimuli to capture attention. In this sense, new onsets are the beneficiaries of any inhibition. Furthermore, a location-based representation of the initial items may first have to be constructed in order to coordinate inhibition to the old items (Watson et al., 2003). Presenting items at isoluminance may impair location coding, and this may, in turn, hamper the generation of location-based inhibition (Livingstone \& Hubel, 1984, 1987). To show that search is affected, to some degree, by the number of old distractors is not the same as showing that these old items have the equivalent impact on search as when they are presented simultaneously with the new stimuli. That is, the study does not demonstrate the absence of a preview benefit, only that it is not perfect (with no impact of the old items on search).

One problem for the account above comes from Donk and Theeuwes's (2001) findings when old items were defined by onsets, whereas new stimuli were isoluminant. In this condition, it ought to have been possible to inhibit the old onset stimuli, facilitating search for the new items. Contrary to this, these researchers claimed that search was again relatively inefficient and was affected by the number of old distractors. Indeed, the variation in RTs as a function of the number of old distractors did not differ from the increases in RTs found as the number of new distractors increased. This suggests that old and new items had an equal impact on search. However, in this study, the background luminance changed across the duration of the preview, so that the old items were isoluminant when the new items appeared. This could have had the effect of eliminating any inhibition applied to locations in a luminance-defined map of the stimuli, since the old items were no longer represented in that map when the new items appeared. Furthermore, a closer inspection of the reported data reveals that, despite these ongoing luminance changes, there was indeed a trend for the slopes of the search functions to be reduced for the old distractors, relative to the new, in this critical condition. Also, only 8 participants were tested, so a strong test of whether there was a reduced impact on search of old stimuli, relative to new, was not provided. In the present study, we carried out a stronger test of whether a preview benefit could occur when the new items were isoluminant, once onset capture was eliminated. In contrast to Donk and Theeuwes, our onset previews remained brighter than the background when isoluminant new items appeared. This might allow inhibition of luminance-defined locations to take place. Also, unlike in Donk and Theeuwes, we included a full-set baseline condition, in which all the items in the final preview display appeared simultaneously. This provided a direct test of whether there would be some preview advantage even if there remained some impact of the old items on search. If new onsets are necessary for the preview advantage (see Donk \& Theeuwes, 2001), performance in the preview condition should not differ when new items are isoluminant, relative to matched full-set baseline conditions.

\section{Overview of the Present Study}

We examined preview search when the old, the new, or both sets of stimuli were isoluminant with the background. We will report three experiments. In Experiment 1, we included four preview conditions: (1) Both the preview and the search displays were presented with an abrupt bright onset, relative to the background $(\mathrm{B}+\mathrm{B})$; (2) both the preview and the search displays were isoluminant, relative to the background (I+I); (3) the preview was isoluminant, and the search display was defined by an abrupt onset (I+B); and (4) the preview appeared with an abrupt bright onset, followed by a search display presented at isoluminance $(\mathrm{B}+\mathrm{I})$. Coupled with these preview conditions were two full-set baseline conditions: (1) All the items were presented with an abrupt onset (matched with the $\mathrm{B}+\mathrm{B}$ preview condition), or all were presented at isoluminance (matched with the I+I preview condition; this varied randomly on a trial by trial basis), or (2) half the items were presented with an abrupt onset, and half were isoluminant with the background. The target occurred in both luminance groups randomly over trials (the mixed-full condition). This mixed luminance baseline was matched to the final display in the preview conditions $(\mathrm{B}+\mathrm{I}$ and $\mathrm{I}+\mathrm{B})$, and it served as a specific test of the onset capture account. In the mixed-full baseline condition, attention should be captured by the onset items, even though the participants cannot predict whether the target is defined by an onset or at isoluminance. If an onset capture effect occurs, the number of items attended should 
be matched with the number of onset items in the $\mathrm{B}+\mathrm{B}$ and $\mathrm{I}+\mathrm{B}$ preview conditions. In other words, there should be no preview advantage. Indeed, as compared with the other preview condition with mixed-luminance items (the $\mathrm{B}+\mathrm{I}$ condition), search in the mixed-full baseline condition should be more efficient when the target is an onset, because attention should be selectively attracted to the onsets, with the isoluminant distractors having little effect on search. In contrast, in the B+I preview condition, attention will not be captured by the isoluminant new items, allowing the old distractors to impact on search. Further predictions concern the preview conditions with isoluminant new stimuli $(\mathrm{B}+\mathrm{I}$ and $\mathrm{I}+\mathrm{I})$ and their respective baselines with isoluminant targets. The $\mathrm{B}+\mathrm{I}$, I+I conditions and the fully isoluminant baseline condition might be advantaged, relative to its mixed-full (no-onset) baseline condition. This would follow if, in the mixed baseline condition, attention is captured by the bright distractors prior to being allocated to the isoluminant distractors and target. The isoluminant target will tend to be found only after the onset distractors have been searched. In contrast, in the other conditions, there are no new onsets to capture search, so that all items compete equally. It follows that the $\mathrm{B}+\mathrm{I}$ and $\mathrm{I}+\mathrm{I}$ preview conditions should not differ from the fully isoluminant baseline. Strikingly, the data from Experiment 1 contradicted these predictions.

One difference between the preview and the mixed-full baseline conditions in Experiment 1 is that, uniquely in the preview condition, the participants could predict the brightness of the target. Even if there was no automatic capture, there could be active anticipation of the target on the basis of its brightness. This would selectively benefit preview search. In Experiment 2, we evaluated this possibility. Two of the preview conditions in Experiment 1 $(\mathrm{B}+\mathrm{I}$ and $\mathrm{I}+\mathrm{I})$ were compared with two full-set baselines conditions: (1) mixed-uncued (in which the target could occur in either luminance group randomly, as in Experiment 1) and (2) mixed-cued. The latter condition involved presenting a set of isoluminant and a set of bright onset stimuli together; however, the target was always isoluminant, and the participants were given valid foreknowledge of the luminance level of the target. As in Experiment 1, if onset capture takes place and, more crucially, solely generates the preview effect, we would expect the same pattern of performance between the B $+\mathrm{I}$ and the I+I preview conditions and the mixed-full (uncued) baseline condition. When the target in the baseline condition is an onset, search in the baseline condition should be more efficient than that in both preview conditions, and when the target is isoluminant, search in the baseline condition may be less efficient than that in the preview condition. On the other hand, new onsets may not be sufficient, but foreknowledge of the target's luminance may be. In this case, search in the mixed-cued condition with isoluminant targets should equal that found in the preview conditions. Whether cuing the luminance of the target has any effect on search can itself be tested in the baseline condition with isoluminant targets. If an anticipatory set is crucial, search efficiency should be greater in the cued than in to the uncued baseline condition.

In Experiment 3, a dual-task procedure was used to again examine whether the preview benefit is caused solely by automatic attentional capture. Prior studies have shown that preview search is selectively disrupted when participants engage in a secondary task during the preview (there is little disruption produced by a secondary task prior to the baseline search conditions; see Humphreys, Watson, \& Jolicœur, 2002; Olivers \& Humphreys, 2002; Watson \& Humphreys, 1997). These findings already contradict the notion of automatic attentional capture, which should take place irrespective of the secondary task. In the present study, we used two dual-task conditions. In the first, the secondary task occurred throughout the duration of the preview, with the items in the preview being bright and new items being isoluminant (based on the B + I condition). There should, in any case, be no onset capture in this condition. If onset capture is critical, there should be little prioritization of new items, with or without the secondary task. A further possibility, though, is that there is attentional capture by new objects even if they are not defined by onsets (see Yantis, 1996). This could account for a preview advantage in the $\mathrm{B}+\mathrm{I}$ condition. If such a capture effect occurs automatically, however, the secondary task during the preview should still have no effect. To foreshadow the results, we found that there was some prioritization of new stimuli (replicating Experiments 1 and 2) but that this was disrupted by the secondary task. In the second dual-task condition, the preview was presented first for $1,000 \mathrm{msec}$, after which the secondary task was introduced (while the preview remained) for 1,000 msec, before the isoluminant new items appeared. In this condition, we manipulated the presence of the first display a full second before the appearance of the new items. If the preview benefit is due to the appearance of the new objects and has nothing to do with the preview, this manipulation should not impact on performance; the new objects remain new objects. Against this prediction, we found that the initial presentation of the preview without the dual task helped to overcome the deleterious effects of the dual task. The findings we will present provide evidence against the argument that new onsets are necessary to generate preview effects and against there being automatic capture of attention by either onsets or new objects. The data from Experiment 3 also point to the possibility that information from the early preview has a useful role in search. The results are consistent with the possibility that preview search is influenced, at least in part, by top-down inhibition of old items in a luminance-defined map. The secondary task reduces the effects of top-down inhibition (Humphreys et al., 2002; Olivers \& Humphreys, 2002; Watson \& Humphreys, 1997). Alternatively, it could be argued that the effects could be due to participants' using the preview to generate an anticipatory set for the new items (Braithwaite \& Humphreys, 2003). However, this anticipatory set would need to be more effective in preview search than in search in the full-set baseline condi- 
tion to explain why there is a preview benefit even when the brightness of the target can be anticipated in the baseline condition (Experiments 2 and 3).

\section{EXPERIMENT 1 The Basic Effect}

Experiment 1 provided a test of the basic effect of the preview condition under isoluminant conditions, with a baseline that was used to assess automatic attentional capture from the new onsets that characterized half the distractors.

\section{Method}

\section{Participants}

Sixteen participants (10 of them female, one left-handed) took part for course credit or a small payment. The age of the participants ranged from 18 to 31 years, with a mean age of 21.7 years. All were undergraduate or postgraduate students at the University of Birmingham. All had self-reported normal or corrected-to-normal vision (including normal color vision).

\section{Stimuli and Apparatus}

All the stimuli and the conditions were generated by a series of computer programs written in Turbo Pascal. The programs were run on a Pentium PC fitted with a 15 -in. Super VGA monitor. These programs recorded all relevant keypress responses and RTs. This set up was used in all the subsequent experiments. The distractor stimuli consisted of multiple colored (green) uppercase I letters at two different orientations $\left(45^{\circ} \mathrm{right} / 45^{\circ}\right.$ left of vertical). This placed both the central line and the two (upper/lower) lines of this letter shape at diagonal orientations. The line junctions where the central line intercepted the end lines were also slightly overrun (by 1 screen pixel) in order to break up the letter shape. The target letter was an uppercase $\mathrm{T}$ or $\mathrm{L}$ at four possible orientations $\left(45^{\circ}, 135^{\circ}, 225^{\circ}\right.$, and $\left.315^{\circ}\right)$. Thus, the displays contained only stimuli consisting of diagonal components. These stimuli were displayed on a blue screen background. The letter stimuli were presented at two different luminance values (depending on the condition; see below). For bright items that arrived with an abrupt onset, the luminance values were fixed. For isoluminant items, the RGB values were set for each participant on the basis of performance from a flicker-fusion color calibration test carried out before the experiment. The fixed settings for the bright items were chosen on the basis of their being sufficient to induce capture while keeping the potential difference relative to the isoluminant items as small as possible (as revealed via pilot studies).

The items were randomly assigned to an invisible 48 individual cell circular matrix. This virtual matrix consisted of three concentric circular ring grids. The distance from central fixation to the middle of the cells of the first ring measured approximately $19 \mathrm{~mm}$ (containing 8 cells), the distance to the second ring was $38 \mathrm{~mm}$ (containing 16 cells), and that to the third was $58 \mathrm{~mm}$ (containing 24 cells). Search displays were generated by randomly positioning each letter in the middle of individual matrix cells. The preview conditions involved the presentation of half (i.e., 12) of the distractor letters first (in the first, preview display), followed by the remaining half (i.e., 12) in the second, search display. The full-set baseline condition involved the simultaneous presentation of the combined preview and the search displays. The target was present on every trial, with it being a rotated $\mathrm{T}$ or $\mathrm{L}$ at random, although each orientation occurred equally often. The participants had to respond by pressing the $\mathrm{T}$ or $\mathrm{L}$ key to correctly identify the target (irrespective of its orientation).

\section{Design and Procedure}

A $6 \times 2$ (condition $\times$ display size) within-subjects design was used. The six experimental conditions consisted of two full-set baseline conditions and four preview conditions. The two full-set baseline conditions were (1) a single presentation of either 12 or 24 items, where all the items could be presented with an onset (brighter relative to the background) or without an abrupt onset (isoluminant with the background) on any given trial (determined randomly; the full-set condition), and (2) a mixed full-set condition, where each display consisted of items that were of mixed luminance-half the items being presented with an onset (brighter than the background), and the other half being isoluminant with the background (the mixed-full condition). In the second condition, the target could occur in either the bright or the isoluminant group equally often, so luminance itself was not predictive of target location (it was irrelevant to the task). RTs for these two trial types were separated in the analysis. Matched with these full-set conditions, there were four preview conditions, in which (1) both the preview and the search sets were presented with bright onsets (both brighter than the background; B+B), (2) the preview and the search sets were both isoluminant $(\mathrm{I}+\mathrm{I}),(3)$ the preview items were isoluminant and the search set was bright $(I+B)$, and (4) the preview was bright and the search items were isoluminant $(B+I)$. Trials within blocks were fully randomized, and block order was randomized across participants. A general block of practice trials, for both preview and baseline conditions, was completed at the beginning of the experiment. None of these practice trials was included in the analysis.

Before taking part in the experiment proper, each participant took part in a color fusion flicker test to establish individual isoluminant values for the green items (matched to the blue background). Each participant was given practice at the flicker test before completing five experimental calibration trials. The final values were based on an average RGB setting from the five trials. These values were then entered into the programs for the displays.

Search trials took the following form. Each trial began with the presentation of a plain white fixation cross, which remained visible until the end of the trial. For the baseline condition, 1,000 msec after fixation onset, the search display was presented and remained visible until a response key was pressed or a timeout period of $10,000 \mathrm{msec}$ had elapsed. This procedure was repeated for each trial for the duration of the experimental block. There was a 1,000-msec delay between the presentations of the individual trials in all the conditions. For the preview conditions, the fixation cross was followed by the preview display for $1,000 \mathrm{msec}$ and then by the target display. The distractors in the preview remained in the same positions when the target display appeared. For the preview presentations, the participants were instructed to remain fixated and not to initiate search until the arrival of the second display (when the target appeared). For these preview conditions, RTs were measured from the onset of the second display. The experiment lasted approximately $50 \mathrm{~min}$.

\section{Results}

The RT data were trimmed for outliers (deemed to be $\pm 2.5 S D$ s and any response faster than $200 \mathrm{msec}$ ) and incorrect responses for each participant. This procedure was used in all the subsequent experiments. An overall $6 \times 2$ (condition $\times$ display size) within-subjects ANOVA revealed significant main effects of condition $[F(5,75)=$ $36.47, p<.001]$ and display size $[F(1,15)=176.85, p<$ $.001]$. The condition $\times$ display size interaction was also significant $[F(5,75)=10.68, p<.001]$.

\section{Performance in the Mixed-Full Baseline}

Performance in the mixed-luminance full-set baseline condition was separated for bright (onset) and isoluminant (no-onset) targets. A $2 \times 2$ (luminance group $\times$ display size) within-subjects ANOVA revealed main effects 
of both luminance group $[F(1,15)=37.16, p<.001]$ and display size $[F(1,15)=96.05, p<.001]$. The luminance $\times$ display size interaction was also significant $[F(1,15)=$ $6.60, p<.05]$. Search performance was faster and more efficient for targets that arrived with an abrupt onset, relative to when they were presented at isoluminance.

\section{Preview Versus Mixed Baselines}

For the full-set mixed-luminance baseline condition, trials were separated on the basis of whether the target was a bright onset item or arrived without an onset (isoluminant to the background). Performance was then compared with the critical preview conditions.

Mixed-full (onset) versus $\mathbf{B}+\mathbf{B}$. The main effects of both condition $[F(1,15)=15.96, p<.01]$ and display size $[F(1,15)=106.54, p<.001]$ were significant. The condition $\times$ display size interaction was also significant $[F(1,15)=13.61, p<.01]$. Search performance was, overall, faster and also more efficient in the $\mathrm{B}+\mathrm{B}$ preview condition, relative to a full-set baseline created by onsets, even though the number of new onsets was the same in these two conditions (see Figure 1).

Mixed-full (onset) versus I+B. The main effects of both condition $[F(1,15)=10.98, p<.01]$ and display size $[F(1,15)=46.14, p<.001]$ were significant. The condition $\times$ display size interaction failed to reach significance $[F(1,15)=1.00, p=.331]$. RTs were, overall, shorter in the preview than in the baseline condition, but the search slopes did not differ across the conditions (see Figure 1).

Mixed-full (onset) versus B+I. The main effects of condition and display size were reliable $[F(1,15)=8.43$, $p<.05$, and $F(1,15)=46.82, p<.001$, respectively]. The interaction between condition and display size did not approach significance $[F(1,15)=1.38, p=.259]$. Although search was overall faster in the baseline condition, there was no gain in search efficiency.

Mixed-full (onset) versus I+I. There were significant effects of condition and display size $[F(1,15)=15.91$, $p<.01$, and $F(1,15)=57.91, p<.001$, respectively] and a reliable interaction $[F(1,15)=6.42, p<.05]$. There was an advantage in terms of search efficiency for the baseline condition with onset targets, as compared with the preview when all the items were isoluminant with the background.

Mixed-full (no onset) versus $\mathbf{I}+\mathbf{I}$. The main effect of condition was significant $[F(1,15)=7.92, p<.05]$. The main effect of display size was significant $[F(1,15)=$ $49.48, p<.001]$. The condition $\times$ display size interaction was not significant $[F(1,15)=0.31, p=.583]$. RTs in the preview condition were overall shorter, but there was no difference between the slopes of the functions for the conditions (see Figure 2).

Mixed-full (no onset) versus $B+I$. The main effects of condition $[F(1,15)=53.29, p<.001]$ and display size $[F(1,15)=116.15, p<.001]$ were significant. The

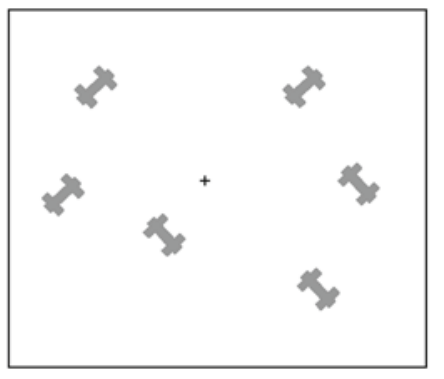

Preview display (condition $\mathrm{B}+\mathrm{I}$ )

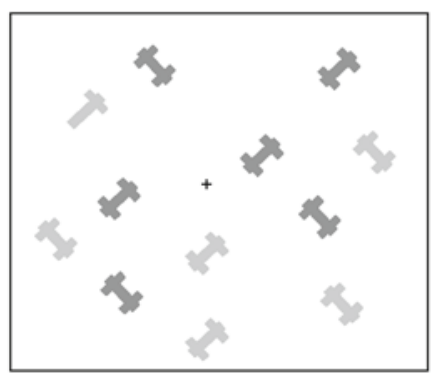

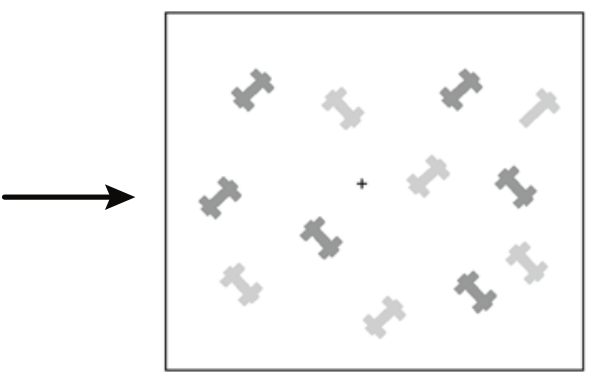

Search display added (condition $\mathrm{B}+\mathrm{I}$ )

Full-set baseline (matched to condition $\mathrm{B}+\mathrm{I}$ )

Figure 1. A schematic illustration of the preview procedure used in the present experiments. The upper panels show preview condition $B+I$. Here, preview items are presented with an abrupt onset (dark gray letters). These are followed by the isoluminant target-carrying search display (light gray letters), which is added after a $1,000-m s e c$ preview duration. In this case, the target is an isoluminant letter $T$. This condition is matched to a full-set baseline presentation, which consists of a simultaneous presentation of all the items (matched to the final combined display from the preview condition). 


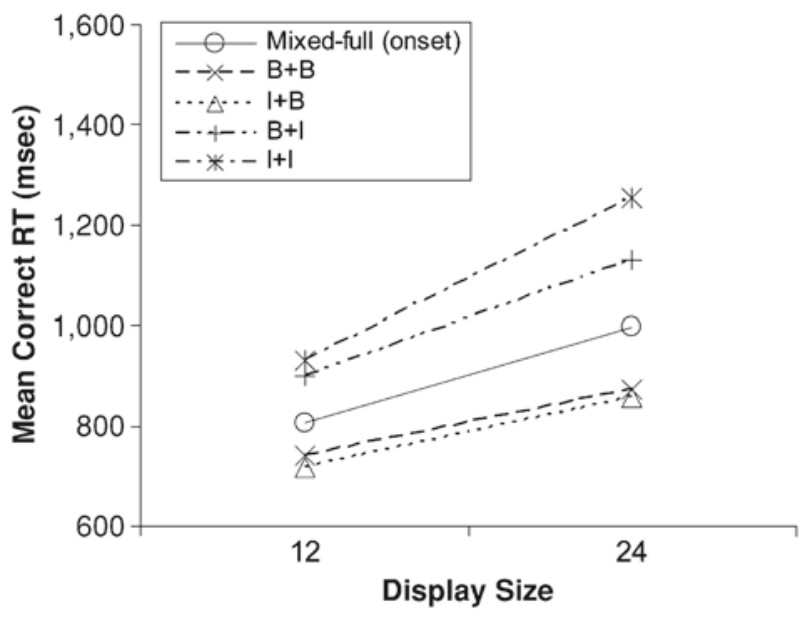

Figure 2. Mean correct reaction times (RTs) for onset targets in the mixed-full baseline and preview conditions $\mathrm{B}+\mathrm{B}, \mathrm{I}+\mathrm{B}, \mathrm{B}+\mathrm{I}$, and $I+I$ in Experiment 1. Preview conditions are denoted by dotted lines, and baseline conditions by solid lines.

condition $\times$ display size interaction was also significant $[F(1,15)=9.99, p<.01]$. Search in the $\mathrm{B}+\mathrm{I}$ preview condition was, overall, faster and more efficient than it was when the target was an isoluminant item in the mixedfull baseline condition (see Figure 2).

\section{Preview Comparisons}

We subsequently compared the preview conditions alone, to test for differences in search efficiency according to the relative brightness of the old and new distractor and target stimuli.

$\mathbf{I}+\mathbf{B}$ versus $\mathbf{B}+\mathbf{B}$. The main effect of condition $[F(1,15)=1.06, p=.319]$ was not significant, although there was a main effect of display size $[F(1,15)=146.94$, $p<.001]$. The condition $\times$ display size interaction was not significant $[F(1,15)=0.07, p=.8]$. Performance in the $\mathrm{I}+\mathrm{B}$ condition was equivalent to that in the $\mathrm{B}+\mathrm{B}$ condition. Having bright, rather than isoluminant, old items had no effect on search efficiency.

$\mathbf{B}+\mathbf{I}$ versus $\mathbf{I}+\mathbf{I}$. The main effects of both condition $[F(1,15)=5.40, p<.05]$ and display size $[F(1,15)=$ $105.96, p<.001]$ were significant. The condition $\times$ display size interaction was also significant $[F(1,15)=$ $5.42, p<.05]$. Search in the $\mathrm{B}+\mathrm{I}$ condition was, overall, quicker and more efficient than that in the I+I condition. This is of some interest, because the old distractors were brighter in the $\mathrm{B}+\mathrm{I}$ condition, than in the $\mathrm{I}+\mathrm{I}$ condition. Bright distractors should compete more for selection than do dimmer isoluminant distractors.

\section{Preview Versus Single-Luminance Baselines}

We finally compared RTs in the full-set baseline condition, in which all the items were either isoluminant or bright, with those in the preview conditions, in which the search set was matched to the properties of the baseline.

Full-set (all onset) versus $\mathbf{B}+\mathbf{B}$. The main effects of both condition $[F(1,15)=15.96, p<.01]$ and display size $[F(1,15)=106.54, p<.001]$ were significant. The condition $\times$ display size interaction was also significant $[F(1,15)=13.61, p<.01]$. RTs were, overall, quicker and more efficient (in terms of search slopes) in the B+B condition than in the full-set baseline condition (see Figure 3 ). This is the standard preview benefit, where all the stimuli are defined by onsets (see Theeuwes et al., 1998).

Full-set (all no onset) versus $\mathbf{I}+\mathbf{I}$. The main effects of both condition $[F(1,15)=7.92, p<.05]$ and display size $[F(1,15)=49.48, p<.001]$ were significant. The condition $\times$ display size interaction was not significant $[F(1,15)=0.31, p=.583]$. Search efficiency was not improved in the preview conditions, relative to this fullset baseline condition (see Figure 3).

\section{Errors}

Overall, the error rate was low at $4.86 \%$. Errors were analyzed similarly to RTs, in an overall $6 \times 2$ (condition $\times$ display size) within-subjects ANOVA. This revealed only a significant main effect of display size $[F(1,15)=7.97$, $p<.05$; all other $F \mathrm{~s}<2]$. There was no evidence of a speed-accuracy trade-off.

\section{Discussion}

The main results from Experiment 1 were as follows. In the mixed-luminance baseline condition, search was faster for onset than for isoluminant targets. This occurred even though both types of targets were equally likely. This is consistent with the suggestion of a privileged role for onsets in the guidance of attention, at least in the absence of any specific attentional set to the contrary (Donk \& Theeuwes, 2001). On the other hand, as we will outline below, at least three pieces of evidence contradict the onset capture account.

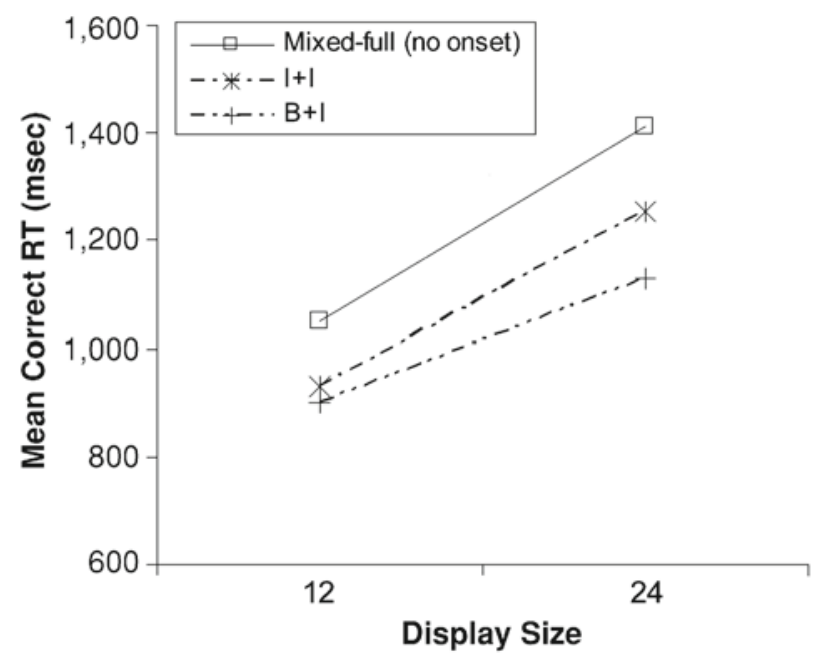

Figure 3. Mean correct reaction times (RTs) for isoluminant targets in the mixed-full baseline condition and for the $I+I$ and $B+I$ preview conditions in Experiment 1. In both preview conditions, the new items appeared without an abrupt onset. 
For the preview conditions, performance was advantaged if both the old and the new items arrived with an onset. For instance, search in the $\mathrm{B}+\mathrm{B}$ condition was more efficient than that in an equivalent full-set baseline condition (containing all bright items). More important, search was also more efficient in the $\mathrm{B}+\mathrm{B}$ preview condition than in the mixed full-set baseline condition in which the target was an onset. This is a crucial result, because the number of new onsets was the same in the preview and the baseline conditions. If there is automatic capture of attention by the new onsets, search should be equally efficient across the conditions. The preview advantage here provides the first evidence against automatic capture as a complete account of preview search. A second result that argues against an onset capture account is that the new items did not have to be defined by an onset to generate a preview advantage. Performance was better in the $\mathrm{B}+\mathrm{I}$ condition than in the mixed full-set baseline condition when the target was isoluminant.

A third piece of evidence is that search efficiency in the $\mathrm{B}+\mathrm{I}$ condition did not differ from that found for onset targets in the mixed full-set baseline condition. An onset capture account holds that the onset stimuli in the baseline condition would be prioritized for selection, so that the target should be found quite efficiently. In the B $+\mathrm{I}$ condition, the new isoluminant items should not be prioritized, so that target detection should be relatively inefficient (with the older distractors being as likely to be selected as the new stimuli). Against this, there was no gain in search efficiency for onset targets in the baseline condition.

Search in the other conditions largely followed prior reports in the literature. The preview condition with all isoluminant items was inefficient and did not differ from the equivalent full-set baseline condition. This matches the data from Donk and Theeuwes (2001). Search in the $\mathrm{I}+\mathrm{I}$ preview condition was also less efficient than that in the $\mathrm{B}+\mathrm{I}$ condition, although the new items were isoluminant in both instances. This suggests that having nonisoluminant previews was important for search. According to a visual-marking account (Watson \& Humphreys, 1997), this is because inhibition is applied to the locations of old items in a luminance-defined map. Alternatively, participants may use the bright preview to develop an expectancy for the isoluminant new items, making search efficient. For the expectancy account, though, it is not clear why a set for the isoluminant new items could not be generated from the isoluminant preview, since the expected target properties would match those of the representation used to generate the expectancy (the preview). Nevertheless, the possible role of expectancies was tested in Experiment 2, where we introduced a cued full-set baseline with mixed-luminance items. If this expectancy plays a role, search should be more efficient in the cued than in the uncued baseline condition. One other result to note here is that search in the $\mathrm{I}+\mathrm{B}$ condition did not differ from that in the $\mathrm{B}+\mathrm{B}$ condition. This result might initially seem difficult for the marking account. If isoluminant items cannot be inhibited, there might be a cost to search from these items' remaining available for selection (in $\mathrm{I}+\mathrm{B}$, as compared with $\mathrm{B}+\mathrm{B}$, where the old stimuli should be marked). However, this supposes that isoluminant items, even if available for selection, have a significant impact on search for bright targets. This may not be the case, and the greater search efficiency for bright targets is shown even in the baseline conditions here. Thus, even though they might not be marked, isoluminant distractors would have little effect on search for a bright onset target. The lack of difference between the $\mathrm{I}+\mathrm{B}$ and the $\mathrm{B}+\mathrm{B}$ conditions remains consistent with a marking account, although we should also note that it fits with an onset capture account too, since only the bright new items should matter in both instances.

\section{EXPERIMENT 2 Baseline With Foreknowledge}

In Experiment 2, we focused on performance with isoluminant new items in the preview conditions $(\mathrm{B}+\mathrm{I}$ and I+I only). Performance was also contrasted in two full-set baseline conditions according to whether or not the target's brightness was cued. Can such an expectancy influence performance and explain the preview benefit?

\section{Method}

Unless otherwise mentioned, the method was the same as that in Experiment 1.

\section{Participants}

Twenty-one participants (2 left-handed) took part for course credit or a small payment. The age of the participants ranged from 19 to 28 years, with a mean age of 21.4 years. All were undergraduate or postgraduate students at the University of Birmingham. All had self-reported normal or corrected-to-normal vision (including normal color vision).

\section{Stimuli and Apparatus}

All the stimuli and the conditions were identical to those in Experiment 1 .

\section{Design and Procedure}

A $4 \times 2$ (condition $\times$ display size) within-subjects design was used. The four experimental conditions consisted of two full-set baseline conditions and two preview conditions. For one full-set baseline condition, we repeated the condition in Experiment 1 in which there was a single presentation of items that were of mixed luminance. Half of the items were brighter than the background, and the other half were isoluminant with the background (mixed-full uncued). The target could occur in either group equally often, so luminance itself was irrelevant. The other full-set baseline consisted of a visually identical condition, but this time the participants were given valid foreknowledge that the target would always occur in the isoluminant group only (mixed-full cued). In this case, the abrupt onset group was irrelevant to the task and never contained the target. These baseline conditions were compared with the $\mathrm{B}+\mathrm{I}$ and $\mathrm{I}+\mathrm{I}$ preview conditions in Experiment 1. The procedure matched that in Experiment 1 . The experiment lasted approximately $40 \mathrm{~min}$.

\section{Results}

The RT data were prepared for analysis in the same way as in Experiment 1. In addition, 1 participant was removed from the analysis for producing high errors $(>15 \%)$ in one cell. For the mixed-luminance uncued baseline condition, 
we separated RTs for onset and isoluminant items and entered these data (from the remaining 20 participants), along with those from the other conditions, into an overall $5 \times 2$ (condition $\times$ display size) within-subjects ANOVA. This revealed significant main effects of condition and display size $[F(4,76)=10.63, p<.001$, and $F(1,19)=148.30$, $p<.001$, respectively]. The condition $\times$ display size interaction was also significant $[F(4,76)=4.88, p<.01]$.

\section{Baseline Comparisons}

For the mixed-full uncued baseline condition, data were analyzed to assess whether there were differences according to the luminance attribute (bright onset vs. isoluminant) of the target. There were significant main effects of target type $[F(1,19)=18.15, p<.001]$ and display size $[F(1,19)=104.48, p<.001]$. The target type $\times$ display size interaction was also significant $[F(1,19)=6.16, p<$ $.05]$. Search was, overall, faster and more efficient when the target was an onset letter than when it was isoluminant with the background. These data replicate those in Experiment 1 . The results are presented in Figure 4.

Mixed-full cued versus mixed-full uncued (noonset targets). The main effects of both condition $[F(1,19)=7.49, p<.05]$ and display size $[F(1,19)=$ $71.02, p<.001]$ were significant. The condition $\times$ display size interaction was not significant $[F(1,19)=1.80$, $p=.195]$. Although providing the observers with foreknowledge of the target luminance group improved overall RTs, actual search efficiency was equivalent across the two conditions.

\section{Mixed-Full Cued Versus Preview Comparisons (All Isoluminant Targets)}

Search performance for isoluminant targets from the mixed-full cued baseline condition in which the participants were given foreknowledge of the target was then compared with that in the preview conditions. These results will be related below.

Mixed-full cued versus $\mathbf{I}+\mathbf{I}$. Only the main effect of display size was significant $[F(1,19)=10, p<.001]$. Neither the main effect of condition $[F(1,19)=2.03$, $p=.171]$ nor the condition $\times$ display size interaction $[F(1,19)=0.01, p=.931]$ was significant.

Mixed-full cued versus $\mathbf{B}+\mathbf{I}$. The main effects of both condition $[F(1,19)=9.70, p<.01]$ and display size $[F(1,19)=90.01, p<.001]$ were significant. The condition $\times$ display size interaction was also reliable $[F(1,19)=5.61, p<.05]$. Search in the $\mathrm{B}+\mathrm{I}$ preview condition was faster and more efficient than that in the equivalent full-set baseline condition, even when the brightness of the target was known in advance. The data for the preview conditions are shown in Figure 5.

\section{Mixed-Full Uncued (Onset Targets) Versus Preview Comparisons}

In a final set of analyses, we compared the two preview conditions with the uncued baseline condition with mixed luminances. This again tested for automatic onset capture in the uncued baseline condition. The onset capture

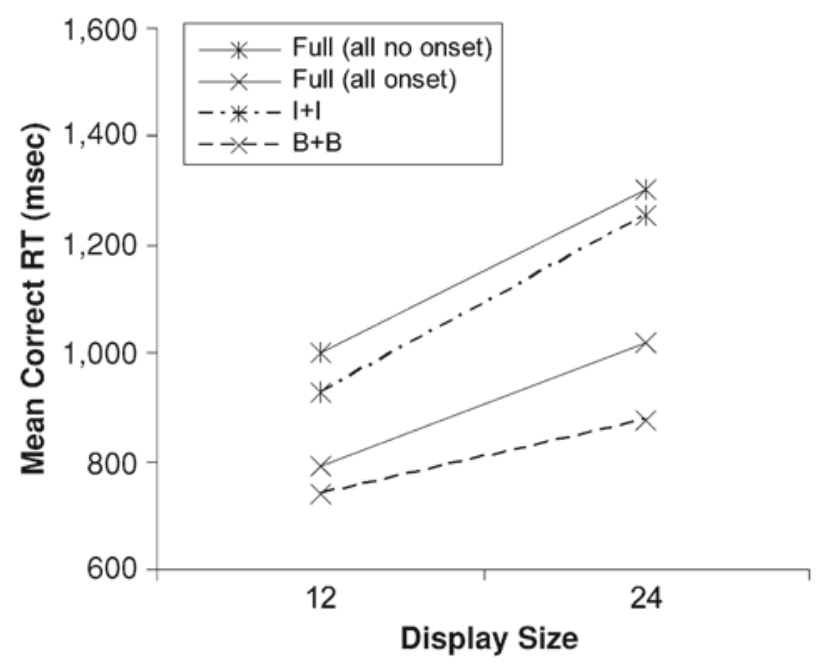

Figure 4. Mean correct reaction times (RTs) for the full-set baseline condition in which all the items were presented either with an abrupt onset or at isoluminance in Experiment 1. These are matched here with the $B+B$ and $I+I$ preview conditions.

view predicts that the onset target in the baseline condition should be prioritized and found more easily than the isoluminant target in the two preview conditions.

Mixed-full uncued (onset) versus B $+\mathbf{I}$. There was a significant effect of display size $[F(1,19)=178.29, p<$ $.001]$. However, there was no effect of condition and no condition $\times$ display size interaction $[F(1,19)=1.00, p>$ .05 , and $F(1,19)=1.19, p>.05$, respectively]. There was no advantage for the onset targets in the baseline condition over isoluminant targets in the preview condition.

Mixed-full uncued (onset) versus $I+I$. There was a main effect of display size $[F(1,19)=179.73, p<.001]$. The main effect of condition $[F(1,19)=3.41, p>.05]$ and the condition $\times$ display size interaction $[F(1,19)=$ $3.46, p>.05$ ] were not reliable (although there were nonsignificant trends for both effects).

\section{Errors}

Overall, the error rate was low at $4.64 \%$. Errors were analyzed in the same way as RTs, in an overall $5 \times 2$ (condition $\times$ display size) within-subjects ANOVA. This revealed only a significant main effect of condition $[F(4,76)=6.01, p<.001]$. The main effect of display size just failed to reach significance $[F(1,19)=3.11, p=$ $.09]$. The condition $\times$ display size interaction was not significant $[F(4,76)=0.56, p=.690]$. There were no signs of a speed-accuracy trade-off.

\section{Discussion}

The general findings in Experiment 2 replicated those in Experiment 1. Search was more efficient in the uncued mixed-luminance baseline when the target came in the onset, relative to the isoluminant group. Cuing the participants to attend to the isoluminant items reduced overall RTs, although it did not improve search efficiency (mea- 
sured in terms of search slopes). The overall RT gain from cuing can be accounted for in various ways. For example, participants may always attend to and search the onset stimuli in such displays, irrespective of whether they know that the target is isoluminant; however, the time to switch to the isoluminant items may be shorter when the participants are cued that the target is always isoluminant. This would generate an RT benefit, but without search being much more efficient. Critically, though, search was more efficient in the $\mathrm{B}+\mathrm{I}$ preview condition than in the a mixed-luminance full-set baseline condition in which where the target's isoluminant status was cued. This finding goes against the idea that the participants were simply directing their attention to the relevant defined luminance group, since were that the case, performance in the B+I condition should be matched to the appropriate full-set baseline (mixed-full, cued, isoluminant). Clearly it was not. These results suggest that search in the preview condition was not based just on an anticipatory set directed toward the isoluminant items. This is also suggested by the advantage for the $\mathrm{B}+\mathrm{I}$ preview condition over the I + I condition, although in both cases an expectancy for new isoluminant items should have been possible. The result also runs counter to any account in terms of onset capture (Donk \& Theeuwes, 2001), since the new items were not defined by onsets in the $\mathrm{B}+\mathrm{I}$ condition. Thus, having the target defined by an onset is not necessary to generate a preview advantage - at least, provided that the old items were not isoluminant. Interestingly, there was no evidence for a preview benefit when both the old and the new items were isoluminant (the I+I condition). This, in turn, suggests that it is not the mere presence of new objects that generates the preview benefit, since the new items were the same in the $\mathrm{B}+\mathrm{I}$ and the $\mathrm{I}+\mathrm{I}$ conditions. Rather, the status of the old items is important. This fits with an account supposing that there is inhibitory filtering of the old items (see Watson \& Humphreys, 2000), which can be achieved more easily when the old items are not isoluminant. This may be because inhibition operates in a system that registers stimuli defined by luminance (Watson et al., 2003) or because location information is represented more accurately when stimuli are defined by luminance and not just by color (at isoluminance; Livingstone \& Hubel, 1984, 1987).

An alternative, anticipatory account can also be proposed. To explain the data, an expectation of the target's luminance alone cannot be sufficient, since that should have operated in the cued baseline conditions. It must be that the preview, or the temporal segmentation between the preview and the search displays, enables a stronger expectation to be generated than in the baseline condition alone.

In Experiment 3, we employed a dual-task procedure to provide a further test of bottom-up factors that operate in preview search. Experiments 1 and 2 have provided evidence against an onset capture view, since we have demonstrated a preview advantage with isoluminant new items. However, rather than capture by new onsets, there may be capture by new objects, which may be defined by their color, rather than by their luminance (Yantis, 1996).

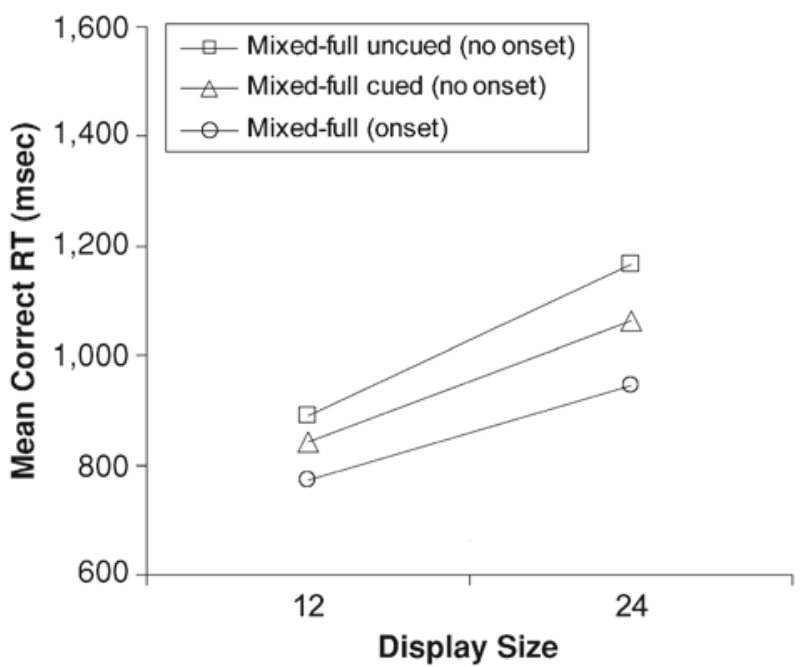

Figure 5. Mean correct reaction times (RTs) for the mixed-full uncued (no onset) targets, as compared with the mixed-full cued (no onset) targets and the mixed-full (onset) targets, in Experiment 2.

If so, a secondary task performed through the preview period should not disrupt the preview advantage (although see Humphreys et al., 2002, Olivers \& Humphreys, 2002, and Watson \& Humphreys, 1997, for prior evidence of the disruptive effects of secondary tasks). We also included one condition in which the preview appeared for $1,000 \mathrm{msec}$ before the secondary task (plus the preview) occurred. This earlier presentation of the preview should be irrelevant for search based on bottom-up allocation of attention to new objects; thus, it should not reduce any effects of the secondary task on performance. In contrast to the onset capture view, the dual task could disrupt search by either reducing inhibitory marking or taking resources away from the expectation of the new items (although the impact on anticipation is assessed further with comparisons with a full-set dual-task condition). When the preview also appears prior to the dual task, marking may benefit, since the representation of the old items may already be coded and an inhibitory process initiated during the early period (see Humphreys et al., 2002). It could also be that the initial preview enables the anticipatory set to be generated prior to attention's being engaged by the secondary task. In either case, the initial (early) preview could mitigate against effects of the secondary task.

\section{EXPERIMENT 3 Dual-Task Effects}

\footnotetext{
Method

\section{Participants}

Twenty-three participants ( 3 left-handed) took part for course credit or a small payment. The age of the participants ranged from 19 to 34 years, with a mean age of 23.2 years. All were undergraduate or postgraduate students at the University of Birmingham. All had self-reported normal or corrected-to-normal vision (including normal color vision).
} 


\section{Stimuli and Apparatus}

The main stimulus difference here, relative to the previous experiments, was the introduction of three new dual-task conditions (one baseline and two preview conditions). All of these involved the presentation of a secondary dual task, presented at isoluminance and at fixation.

\section{Design and Procedure}

A $5 \times 2$ (condition $\times$ display size) within-subjects design was used. The standard mixed luminance full-set baseline and $\mathrm{B}+\mathrm{I}$ preview conditions from Experiment 2 were repeated here. Coupled with these were three new dual task search conditions. The secondary dual task consisted of an isoluminant number sequence presented at fixation for $1,000 \mathrm{msec}$. This sequence contained numbers between 0 and 9 . The individual numbers were flipped every $200 \mathrm{msec}$ into another number in a pseudorandom order (so that the target number always occurred after distractor numbers). The task was to monitor this number stream for the occurrence of the target number 2 . The observers were told that this target number would always occur in the stream but could be presented once, twice, or three times. Once the number sequence had stopped, the second search display was presented, and they had to search for the target letter, as in Experiments 1 and 2. However, at the end of this task, the observers were asked "how many times did the number 2 occur in the number stream?" Accuracy on this task was recorded. The three new search conditions were (1) a full-set baseline condition in which a secondary dual task was presented for $1,000 \mathrm{msec}$ before the presentation of the search display (full-DT), (2) a B+I preview condition in which the dual task occurred as soon as the preview items were presented and continued for the preview duration $(\mathrm{BDT}+\mathrm{I})$, and (3) a B+I preview condition in which the preview items were presented for $1,000 \mathrm{msec}$ before the secondary task, which then continued with the preview for a further $1,000 \mathrm{msec}(\mathrm{pvBDT}+\mathrm{I})$. In all cases, the dual task ceased with the presentation of the second search display. The experiment lasted approximately $45 \mathrm{~min}$.

\section{Results}

The data were made fit for analysis in the manner outlined earlier, with the analyses carried out on mean correct RTs. An initial overall $5 \times 2$ (condition $\times$ display size) within-subjects ANOVA revealed significant main effects of condition and display size $[F(4,88)=27.50$, $p<.001$, and $F(1,22)=219.90, p<.001$, respectively $]$. The condition $\times$ display size interaction was also significant $[F(4,88)=3.16, p<.05]$. Performance was further explored using a series of $2 \times 2$ ANOVAs comparing the preview conditions with the baseline conditions and with each other for an estimate of preview benefits.

\section{Preview Versus Baselines}

Mixed-full cued (no-onset) versus $B+I$. The main effects of both condition $[F(1,22)=9.32, p<.01]$ and display size $[F(1,22)=111.06, p<.001]$ were significant. The condition $\times$ display size interaction was also significant $[F(1,22)=6.40, p<.05]$. Search was, overall, faster and more efficient in the preview condition than in the full-set baseline condition (see Figure 6). This replicates the preview benefit in Experiment 2.

Full-DT versus BDT $+\mathbf{I}$. The $\mathrm{BDT}+\mathrm{I}$ preview condition, in which the dual task occurred throughout the preview period, was assessed relative to the comparable dual-task full-set baseline condition. Only the main effect of display size was significant $[F(1,22)=166.54$,

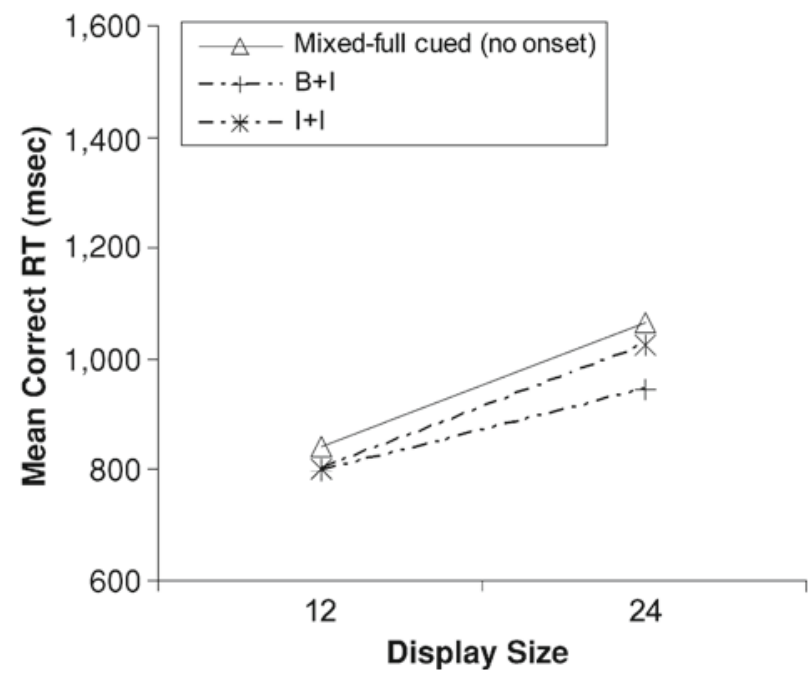

Figure 6. Mean correct reaction times (RTs) for isoluminant (no-onset) targets from the cued mixed full-set baseline and the $B+I$ and $I+I$ preview conditions in Experiment 2. Note that in all cases, the target was a new isoluminant item and the observers were cued to this fact.

$p<.001]$. Both the main effect of condition $[F(1,22)=$ $2.74, p=.112]$ and the condition $\times$ display size interaction $[F(1,22)=0, p=.989]$ were not significant. There was no preview benefit when the observers were given a secondary dual task during the preview period (see Figure 7).

Full-DT versus pvBDT + I. The pvBdT + I preview condition, in which the observers received a preview of $1,000 \mathrm{msec}$ before the secondary task began, was also compared with the full-set baseline condition. This produced a significant main effect of condition $[F(1,22)=$

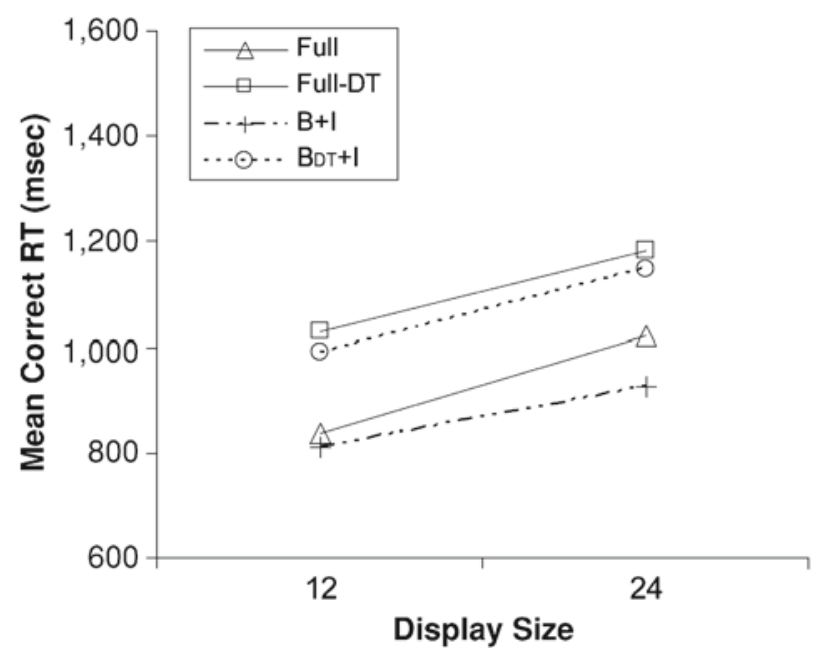

Figure 7. Mean correct reaction times (RTs) for the singleand dual-task full-set baseline conditions (solid lines) and the single- and dual-task preview conditions (dashed lines) in Experiment 3. 
$6.69, p<.05]$ and a significant main effect of display $[F(1,22)=92.42, p<.001]$. The condition $\times$ display size interaction was also significant $[F(1,22)=7.61, p<$ $.05]$. Search in the preview condition was faster and more efficient, relative to the full-set baseline condition (see Figure 8).

\section{Preview Comparisons}

$\mathbf{B}+\mathbf{I}$ versus BDT $+\mathbf{I}$. The main effects of both condition and display size were significant $[F(1,22)=49.57$, $p<.001$, and $F(1,22)=153.90, p<.001$, respectively]. The condition $\times$ display size interaction was also significant $[F(1,22)=4.90, p<.05]$. The dual task reduced search efficiency in the preview condition.

BDT + I versus pvBDT + I. The preview dual-task conditions were compared with each other. This revealed significant main effects of condition $[F(1,22)=6.95, p<$ $.05]$ and display size $[F(1,22)=107.07, p<.001]$. The condition $X$ display size interaction was also significant $[F(1,22)=7.41, p<.05]$. Search efficiency was reliably improved when the observers were given an additional preview of the initial items before the dual task occurred, relative to a condition in which the dual task occurred throughout the preview display.

\section{Full-Set Comparisons}

Full versus full-DT. There was a significant main effect of condition $[F(1,22)=25.14, p<.001]$ and a significant main effect of display size $[F(1,22)=168.49$, $p<.001]$. The condition $\times$ display size interaction was not significant $[F(1,22)=0.63, p=.435]$. Although performance for the dual-task full-set baseline was slower overall, there was no cost to search efficiency.

\section{Errors}

For target search RTs, the overall error rate was low at $2.48 \%$. These errors were analyzed in an overall $5 \times 2$

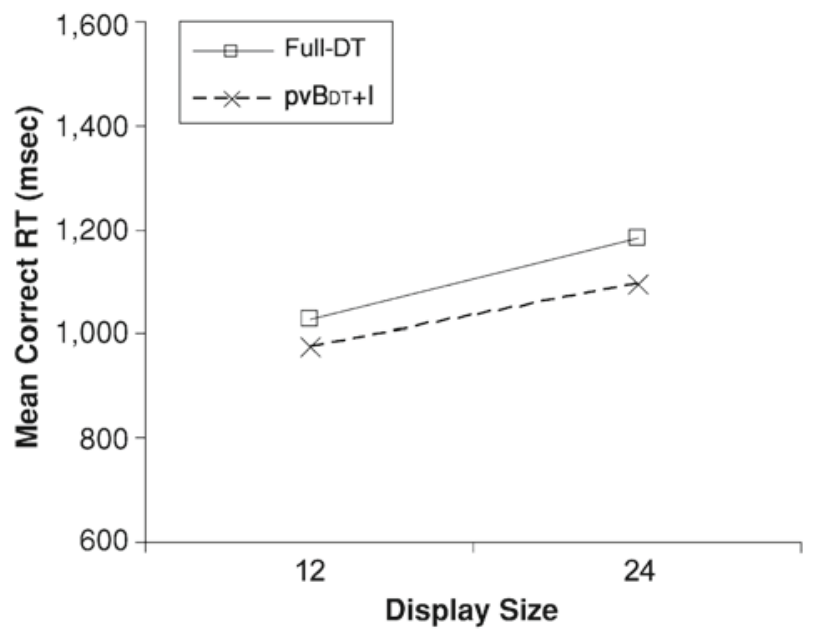

Figure 8. Mean correct reaction times (RTs) for the dual-task baseline, as compared with the pvBvI + I preview condition. (condition $\times$ display size) ANOVA. This revealed main effects of both condition $[F(4,88)=6.91, p<.001]$ and display size $[F(1,22)=10.06, p<.01]$. The condition $\times$ display size interaction was not significant $[F(4,88)=$ $0.14, p=.966]$. The main effect of condition seems to have been due mainly to fewer errors occurring overall in the dual-task conditions. There was no evidence here for a speed-accuracy trade-off. We also looked at the pattern of errors for the secondary number sequence detection task across the three dual-task conditions. The overall error rate was $4.47 \%$. This was explored further in a $3 \times 2$ (condition $\times$ display size) ANOVA that revealed only a main effect of display size $[F(1,22)=15.16, p<.01$; all other $F_{\mathrm{s}}<1$ and $\left.p \mathrm{~s}>.05\right]$. Similar to search errors, there were more number detection errors for the larger display size.

\section{Discussion}

The results of Experiment 3 are consistent with the findings from both Experiments 1 and 2. First, there was a reliable benefit to search efficiency for the $\mathrm{B}+\mathrm{I}$ preview condition when it was compared with the mixed-full cued baseline condition. This result cannot be explained in terms of a simple anticipatory weighting of a known target feature value, since this should have been equal for both conditions. Alternative possibilities are that there is inhibition of old onset previews or that the previews (specifically) are used to generate an anticipatory set for the new isoluminant items.

Second, the preview benefit on search efficiency was abolished for the BDT + I condition, but not for the pvBDT + I condition. This disruptive effect of the secondary task on preview search replicates prior findings in the literature (Humphreys et al., 2002; Olivers \& Humphreys, 2002; Watson \& Humphreys, 1997) and contradicts an account in terms of automatic capture either by new onsets (Donk $\&$ Theeuwes, 2001) or by new objects (Yantis, 1996). The new onset account is doubly contradicted by the evidence of a preview benefit when the new items are isoluminant. On the other hand, the secondary task could either reduce inhibition of the old items or make an anticipatory set less effective.

The different performance between the dual-task fullset baseline (full-DT) condition and the standard full-set condition is interesting in this respect. For instance, there was no cost to search efficiency in the full-DT condition, relative to the standard full-set baseline condition with no dual task. If it were the case that the dual task was critically interfering with top-down anticipatory processes directed to upcoming items, we would expect a cost to search efficiency in the full-DT baseline condition. The fact that there was no cost to anticipating and directing search to the isoluminant set under dual-task conditions makes it unlikely that the dual task has a critical impact upon any anticipatory search processes.

Interestingly, a preview benefit was reestablished when the preview occurred $1,000 \mathrm{msec}$ prior to the onset of the secondary task. It is difficult to understand why this would occur if bottom-up attention to the new search 
stimuli alone was crucial. A similar result was reported by Humphreys et al. (2002) when they used an auditory secondary task. Humphreys et al. (2002) and Watson and Humphreys (1997), however, found that the early presentation of the preview did not alleviate performance with a visual secondary task, where bright numbers had to be monitored at fixation. Humphreys et al. (2002) interpreted these results in terms of a two-stage account of processing previews: There is an initial encoding stage, followed by a maintenance stage in which a representation of the preview is maintained and inhibited (see Humphreys et al., 2004, for converging evidence with a probe dot procedure). They suggested that the initial encoding stage required modality-independent resources, making it vulnerable to interference from both auditory and visual secondary tasks. In contrast, the maintenance stage required only modality-specific resources and so was affected by visual, and not auditory, secondary tasks. Thus, there was no interference from an auditory secondary task that was engaged in after the preview had been encoded. The present data, however, resemble those previously reported with an auditory, rather than with a visual, secondary task. This, in turn, suggests that the modality of the presentation of the secondary task may be less important than whether the task draws attention to the center of the display. In Humphreys et al. (2002), the bright numbers used in the secondary task could have forced participants to attend to the center of the preview display, making it harder to maintain (and inhibit) the locations of the old items. In the present study, the numbers in the secondary task were isoluminant with the background and may not have produced such a degree of attentional focus at the center of the display. Once encoded, the preview representation may still be maintained under these conditions. For a visual-marking account, the early presentation of the preview enables the old items to be encoded and an inhibitory set established.

One further alternative account for the pattern of performance could be that the preview benefits simply reflect an improved disengagement from the initial items that is not possible under simultaneous full-set situations. The argument here would state that, in the $\mathrm{B}+\mathrm{I}$ condition, the preview items do capture attention. However, over the 1,000 -msec preview duration, this capture simply dissipates, releasing attention, which can now be directed toward upcoming events more effectively. Under the full-set conditions, the onset items occur simultaneously with the isoluminant items, so presumably attention cannot fully disengage for some time. So, by this account, the preview benefits could reflect a low-level bottom-up decaying of capture, and not inhibition. Although it is certainly the case that in the full-set conditions the onset items will initially capture attention (a point we acknowledged in the Discussion section of Experiment 1), it is unlikely that this can explain the crucial pattern of performance here. For instance, it is not clear why such disengagement did not occur at all during the BDT $+\mathrm{I}$ condition. A top-down secondary task should have no consequence for such a low-level mechanism. If this were crucial, a benefit should have occurred in this preview condition. Furthermore, it is unlikely that a simple disengagement account would predict a cost to actual search efficiency. In the full-set baseline condition, disengaging from the onset items will produce an overall cost in time (i.e., an intercept), but once attention has been successfully engaged with the isoluminant items, search will be based on the same number of items as that in the isoluminant group in the preview $\mathrm{B}+\mathrm{I}$ condition. In order for the disengagement account to work, there would need to be a viable reason for why disengagement from bright onsets may not be optimal in the baseline condition, relative to the preview condition. We will return to this possibility in the General Discussion section.

Collectively, the results across the experiments presented here suggest that onsets have an important, although not a necessary or absolute, role in mediating preview search performance. These findings are in line with the results of other studies that have revealed the copresence of both capture influences and top-down expectancies for either a target attribute (e.g., Braithwaite \& Humphreys, 2003; Braithwaite et al., 2004) or a targetcarrying display (Atchley et al., 2003). Under those and the present circumstances, visual marking can be seen to be a mechanism that further aids capture processes. Searching complex displays over both space and time is likely to involve a legion of processes that act in concert to produce effective sustained selection.

\section{GENERAL DISCUSSION}

In the present article, we have reported three experiments in which the role of abrupt onsets for the preview benefit in search was examined. Unlike Donk and Theeuwes (2001), we compared performance in the preview conditions with that in the simultaneous baseline conditions, to assess whether any preview benefit was apparent (even if a full benefit was not achieved). The experiments show that a preview benefit occurred whenever the preview items arrived with an abrupt onset and were defined by a luminance difference (irrespective of whether the new items were isoluminant or not). This finding cannot be explained in terms of attentional capture by new onsets (i.e., in the $\mathrm{B}+\mathrm{I}$ condition, the new items are not created by onsets).

The proposal that there is automatic attentional capture by new onsets also has difficulties with other results. In Experiment 1, we used a mixed full-set baseline conditions in which there was the same number of onset stimuli as in the preview conditions with new onsets (i.e., B+B). On the basis of new onset capture, these conditions should have been equivalent. Instead, we found a preview advantage. Also, according to the automatic onset capture account, search in the B+I condition should have been worse than when onset targets occurred in the mixed fullset baseline condition. In the baseline condition, only half the stimuli (the onset target and onset distractors) should 
compete for selection. In the $\mathrm{B}+\mathrm{I}$ condition, all the stimuli should compete. In contrast to this prediction, search efficiency did not differ between these conditions.

As well as providing evidence against an onset capture view, the present data go against two other accounts: that there is only automatic attentional capture by new objects, and that there is simply top-down guidance of search to stimuli defined by their brightness. The new object capture account is contradicted by the finding on dual-task interference, which completely eliminated the preview benefit in the $\mathrm{B}+\mathrm{I}$ condition. It is also unclear why new object capture should not lead to a preview benefit in the I + I condition, since new isoluminant items appeared then too. The guidance-by-brightness account has problems, because this guidance was possible in the cued baseline conditions in Experiments 2 and 3. Nevertheless, there remained a preview advantage.

\section{Evidence for Bottom-Up Guidance}

Although we have argued that new onset or new object capture cannot explain the preview benefit, we do not mean to argue that new onsets have no impact on search. For example, the results from the mixed full-set baseline conditions in Experiments 1 and 2 showed that search performance was advantaged for targets that arrived with an abrupt onset. Also cuing the participants to attend to isoluminant targets led only to a generally reduced RT, without affecting search efficiency-a result consistent with the onset stimuli still being prioritized in search even when they were not cued (but with faster switching to the isoluminant group in the cued condition). In addition to these results in the baseline condition, some results from the preview condition are consistent with effects of bottomup prioritization. In particular, there was no difference in search efficiency between the $\mathrm{I}+\mathrm{B}$ and the $\mathrm{B}+\mathrm{B}$ conditions. In the $\mathrm{I}+\mathrm{B}$ condition, there may be little impact of the old items on search, because their luminance contrast is less than that of the onset stimuli. This may produce a roughly equal benefit to any inhibition of old onset stimuli in the $\mathrm{B}+\mathrm{B}$ condition. So search may be matched here-although, we suggest, for different reasons.

\section{The Preview Benefit}

The most important result here, for interpreting the preview benefit, is that new onsets are not necessary for the preview effect. There can be a preview benefit for new isoluminant stimuli, but apparently only when the old items are not isoluminant (in the $\mathrm{B}+\mathrm{I}$ condition). This result is consistent with the idea that there is inhibitory marking of old items defined by onsets. Provided that resources are available to implement this inhibition, old items will show reduced competition with new stimuli, as compared with when all the items appear together. Under isoluminant conditions either there is no inhibition, since it is applied to a luminance-based representation, or any inhibition is relatively ineffective, because only coarse location information is available (Livingstone \& Hubel,
1984, 1987). An alternative view that we have considered is that the preview is used to establish an anticipatory set to the target on the basis of its brightness. Such an anticipatory set would need to be more effective in the preview than in the baseline condition, in order to explain the preview benefit. However, it is not clear, on this account, why the $\mathrm{I}+\mathrm{I}$ condition as well as the $\mathrm{B}+\mathrm{I}$ condition, did not also lead to a preview benefit, since a set based on the brightness of the new items ought to be established from the isoluminant, as well as the onset, preview display. Furthermore, a simple anticipation account cannot explain the difference in performance across both dual-task preview conditions in Experiment 3. In Experiment 3, performance was impaired for the BDT + I preview condition, but not for the pvBDT + I condition. The scope for and the nature of any anticipation across these conditions were the same. The only difference between the preview conditions was that in the pvBDT + I condition, the participants were given a 1,000-msec preview (with no dual task) before the dual task began. So this difference is concerned with the old items, not the new. If the observers were simply using a strategy of prioritizing the known feature value of the target set (i.e., the isoluminant second set), search performance should be matched across these conditions. Clearly, this was not the case here. The data from the fullset baseline conditions also go against a simple anticipatory account. For instance, there was no cost to search efficiency in the dual-task full-set condition, relative to the standard full-set baseline condition with no dual task. If it were the case that the dual task was critically interfering with top-down anticipatory processes, we would expect a cost in search efficiency in the full-DT baseline condition. The fact that there was no cost to anticipating and directing search to the isoluminant set under dual-task conditions makes it unlikely that the dual task had a critical impact upon any anticipatory search processes.

One other account of preview search not discussed extensively yet is that performance benefits simply from temporal segmentation of the old and the new items (Jiang, Chun, \& Marks, 2002). Efficient temporal segmentation itself may depend on the presence of onsets defining the old and new items, explaining why preview search is no better than that in the full-set baseline condition when all the stimuli are isoluminant (I+I condition). However, temporal segmentation ought to be contingent on the onset of the new displays, as well as the old, yet we found a benefit even when the new stimuli were isoluminant. Also, the temporal account cannot explain why the dual task in the BDT + I condition in Experiment 3 disrupted performance, relative to the $\mathrm{B}+\mathrm{I}$ condition. Here, the temporal parameters of the display were kept constant, yet there were clear and substantial influences of the secondary task on performance.

A final alternative account could be that in preview conditions such as $\mathrm{B}+\mathrm{I}$, the level of initial activation associated with the onset preview items does capture attention but that it rapidly decays. So here, any advantage is 
seen not as active inhibition but as more passive decay of the onset activation. One difference between the full-set baseline and the preview conditions is that in the preview conditions, observers are presented with the onset items first, before the target-carrying isoluminant items are added to the display. From this, it could be argued that the search benefits observed for the $\mathrm{B}+\mathrm{I}$ condition could reflect an improved disengagement from the initial items that is not possible under simultaneous full-set situations. According to this position, attentional capture for the initial onset items simply decays over the preview period, allowing attention to be disengaged and to be deployed more effectively elsewhere. Under the full-set conditions, the onset items occur simultaneously with the isoluminant items, so presumably attention cannot fully disengage for some time. On this view, the preview benefits reflect a low-level bottom-up decaying of attentional capture that, in turn, releases attention after some time.

However, it is unlikely that this account can explain the crucial pattern of performance here. For instance, a bottom-up, low-level decay process should impact on all preview conditions equally, irrespective of other tasks taking place. In contrast, having participants engage in a secondary task eliminated the preview benefit.

Furthermore, it is unlikely that a simple disengagement account would predict a cost to search efficiency in the baseline condition, as compared with an effect on the intercept of the function. In the full-set baseline condition, disengaging from the onset items will produce an overall cost in time (i.e., an intercept), but once attention is successfully engaged with the isoluminant items, search should be based on the same number of items as in the isoluminant group in the $\mathrm{B}+\mathrm{I}$ preview condition.

\section{Implications for Accounts of Preview Search}

The findings presented here are fully consistent with recent developments of the inhibitory visual-marking account, which argues that inhibition is applied to the locations of items that have been coded within a system sensitive to luminance change and spatial discontinuities. Such a mechanism improves the detection of subsequent stimuli that appear within the same luminance-defined system (Watson \& Humphreys, 2002; Watson et al., 2003). According to the inhibitory account, marking arises, in part, because inhibition is applied to the items represented within a luminance-defined system, so that additional items subsequently appearing within the same luminance-defined system (e.g., new abrupt onsets) enjoy an improved signal-to-noise ratio. The present study shows that the new items do not need to appear within a luminance-defined system in order to enjoy a selection advantage. Thus, inhibitory marking can operate so as to bias attention away from inhibited old locations in order to prioritize new stimuli, even when those new stimuli do not generate a luminance-defined signal (Watson \& Humphreys, 1997, 1998, 2000).
We conclude that, across all the data presented here, the account of preview search in terms of visual marking (Watson \& Humphreys, 1997) provides the most consistent framework. This is not to rule out the possibility that other factors cannot also play a role. As we have indicated above, new onsets can help prioritize selection, and an anticipatory set for new items can generate added benefits (see Atchley et al., 2003, and Braithwaite \& Humphreys, 2003 , for further evidence). Crucially, though, on the basis of a detailed and critical reassessment of the published data from prior demonstrations of capture effects (i.e., Donk \& Theeuwes, 2001) and the new evidence presented here, we suggest that new onsets are not necessary.

\section{REFERENCES}

Atchley, P., Jones, S. E., \& Hoffman, L. (2003). Visual marking: A convergence of goal- and stimulus-driven processes during visual search. Perception \& Psychophysics, 65, 667-677.

BraithwaIte, J. J. (2002). Visual search in space and time: Where attention and inattention collide? Unpublished doctoral dissertation, University of Birmingham.

Braithwaite, J. J., \& Humphreys, G. W. (2003). Inhibition and anticipation in visual search: Evidence from effects of color foreknowledge on preview search. Perception \& Psychophysics, 65, 213-237.

Braithwaite, J. J., Humphreys, G. W., \& Hodsoll, J. (2003). Color grouping in space and time: Evidence from negative color-based carryover effects in preview search. Journal of Experimental Psychology: Human Perception \& Performance, 29, 758-778.

Braithwaite, J. J., Humphreys, G. W., \& Hodsoll, J. (2004). Effects of colour on preview search: Anticipatory and inhibitory biases for colour. Spatial Vision, 17, 389-415.

Braithwaite, J. J., Humphreys, G. W., \& Hulleman, J. (2005). Color-based grouping and inhibition in visual search: Evidence from a probe detection analysis of preview search. Perception \& Psychophysics, 67, 81-101.

Donk, M., \& Theeuwes, J. (2001). Visual marking beside the mark: Prioritizing selection by abrupt onsets. Perception \& Psychophysics, 63, 891-900.

GiBSON, B. S., \& JIANG, Y. (2001). Visual marking and the perception of salience in visual search. Perception \& Psychophysics, 63, 59-73.

Humphreys, G. W., Jung Stalmann, B., \& Olivers, C. [N. L.] (2004). An analysis of the time course of attention in preview search. Perception \& Psychophysics, 66, 713-730.

Humphreys, G. W., Watson, D. G., \& Joliceur, P. (2002). Fractionating visual marking: Dual-task decomposition of the marking state by timing and modality. Journal of Experimental Psychology: Human Perception \& Performance, 28, 640-660.

Jiang, Y., Chun, M. M., \& Marks, L. E. (2002). Visual marking: Selective attention to asynchronous temporal groups. Journal of Experimental Psychology: Human Perception \& Performance, 28, 717730.

Livingstone, M. S., \& Hubel, D. H. (1984). Anatomy and physiology of a color system in the primate visual cortex. Journal of Neuroscience, 4, 309-356.

Livingstone, M. S., \& Hubel, D. H. (1987). Psychophysical evidence for separate channels for the perception of form, color, movement, and depth. Journal of Neuroscience, 7, 3416-3468.

Olivers, C. N. L., \& HumphreYs, G. W. (2002). When visual marking meets the attentional blink: More evidence for top-down, limited capacity inhibition. Journal of Experimental Psychology: Human Perception \& Performance, 28, 22-42.

Olivers, C. N. L., \& Humphreys, G. W. (2003). Visual marking and singleton capture: Fractionating the unitary nature of visual selection. Cognitive Psychology, 47, 1-42. 
Olivers, C. N. L., Watson, D. G., \& Humphreys, G. W. (1999). Visual marking of locations and feature maps: Evidence from withindimension defined conjunctions. Quarterly Journal of Experimental Psychology, 52A, 679-715.

Theeuwes, J., Kramer, A. F., \& Atchley, P. (1998). Visual marking of old objects. Psychonomic Bulletin \& Review, 5, 130-134.

Watson, D. G. (2001). Visual marking in moving displays: Featurebased inhibition is not necessary. Perception \& Psychophysics, 63, $74-84$

Watson, D. G., \& Humphreys, G. W. (1997). Visual marking: Prioritizing selection for new objects by top-down attentional inhibition of old objects. Psychological Review, 104, 90-122.

WAtson, D. G., \& HumphreYs, G. W. (1998). Visual marking of moving objects: A role for top-down feature-based inhibition in selection Journal of Experimental Psychology: Human Perception \& Performance, 24, 946-962.

Watson, D. G., \& Humphreys, G. W. (2000). Visual marking: Evi- dence for inhibition using a probe-dot detection paradigm. Perception \& Psychophysics, 62, 471-481.

Watson, D. G., \& Humphreys, G. W. (2002). Visual marking and visual change. Journal of Experimental Psychology: Human Perception \& Performance, 28, 379-395.

Watson, D. G., Humphreys, G. W., \& Olivers, C. N. L. (2003). Visual marking: Using time in visual selection. Trends in Cognitive Sciences, 7, 180-186.

Yantis, S. (1993). Stimulus-driven attentional capture. Current Directions in Psychological Science, 2, 156-161.

YANTIS, S. (1996). Attentional capture in vision. In A. F. Kramer, M. G. H. Coles, \& G. D. Logan (Eds.), Converging operations in the study of visual selective attention (pp. 45-77). Washington, DC: American Psychological Association.

(Manuscript received February 26, 2004;

revision accepted for publication December 23, 2004.) 